\title{
As políticas públicas, a autonomia, a interculturalidade e as discussões bioéticas
}

\author{
Tatiana Bragança de Azevedo Della Giustina ${ }^{1}$, José Hiran da Silva Gallo ${ }^{1}$, Rui Nunes ${ }^{2}$
}

1. Conselho Federal de Medicina, Brasília/DF, Brasil. 2. Universidade do Porto, Porto, Portugal.

A pandemia segue causando grande impacto na saúde e na economia mundial, e desencadeando questionamentos constantes à área da saúde e à sociedade. Nesse contexto, o papel do Estado no financiamento adequado dos serviços de saúde é fundamental, pois a pandemia de covid-19 tem diferentes repercussões em razão da iniquidade de condições em que as pessoas vivem. Assim, a falta de saneamento básico, por exemplo, dificulta - e, em alguns casos, impede - a tomada de medidas preventivas necessárias para conter os desastrosos efeitos da pandemia.

Embora o coronavírus ataque a todos de forma indistinta, a maior parte das pessoas afetadas vive na informalidade, não pode fugir de aglomerações, não possui infraestrutura para trabalhar em sua própria casa mantendo o salário e não tem uma renda mínima básica garantida pelo governo para sua sobrevivência ${ }^{1}$. É preciso haver uma perspetiva abrangente do modelo de sociedade que se pretende construir para um combate eficaz à pandemia de covid-19. Desde logo, todos, sem exceção, devem ter acesso a condições humanitárias básicas e a sociedade tem a responsabilidade de construir um modelo de bem-estar social consentâneo às modernas democracias do século XXI.

Dado que a pandemia de covid-19 é um problema internacional, encontrar soluções eficazes e efetivas para todos os povos é uma questão de justiça global. O índice de desenvolvimento humano, preconizado pelo filósofo e economista Amartya Sen ${ }^{2}$, ganhador do Prêmio Nobel de Economia em 1998, não mede o desenvolvimento e a qualidade de vida apenas em função de critérios materiais, pois inclui também fatores como educação, saúde, liberdade e usufruto dos direitos humanos. Neste período de crise, a importância dessas questões é salientada e respostas globais são necessárias, pois a implementação de políticas públicas deve ter o objetivo de corrigir distorções.

Outro tema abordado são as diretivas antecipadas de vontade (DAV) em pacientes com doença de Alzheimer. O envelhecimento progressivo da população em todo o mundo, ocorrido partir do século XX, resultou no aumento das doenças degenerativas crônicas, eventualmente incapacitantes, que muitas vezes progridem para a demência ${ }^{3}$. Trata-se mesmo de outra "pandemia" com a qual as sociedades contemporâneas devem aprender a conviver, sempre respeitando os direitos dos mais idosos com carinho e compaixão.

Em abril de 2012, a Organização Mundial da Saúde ${ }^{4}$ publicou documento em que coloca a demência como prioridade de saúde pública, considerando a qualidade de vida das pessoas com idade avançada. Estudos projetam crescimento continuado no número de pessoas com demência, especialmente com mais de 85 anos de idade ${ }^{3}$, mas, ainda que não exista um tratamento capaz de deter ou reverter o 
processo de demência, é possível fazer um planejamento a respeito dos cuidados médicos. $\mathrm{O}$ avanço das tecnologias na área médica prolonga a vida dos indivíduos, porém é preciso garantir a autonomia e a autodeterminação, para evitar tratamentos inaceitáveis - dentro dos valores de cada pessoa -, antes da fase mais avançada da doença, quando o paciente já não é capaz de decidir suas preferências ${ }^{3}$.

As DAV minimizam a incidência de mistanásia, morte miserável de muitos idosos, que sequer têm acesso aos hospitais públicos deste país. Da mesma forma, elas evitam a distanásia, compreendida como postergação da morte que muitas vezes apenas prolonga o sofrimento ${ }^{5}$. Nesse sentido, na forma de um testamento vital ou procuração de cuidados de saúde, as DAV têm também uma importante externalidade positiva, que é o reforço da responsabilidade individual em tomar decisões por e para si, e a responsabilidade coletiva em cuidar de quem mais necessita.

Em seguida, debate-se a indicação de conduta cirúrgica em casos de tumores de tronco encefálico, que representam $10 \%$ a $20 \%$ dos tumores do sistema nervoso central em crianças. Nesse grupo, o tumor mais frequente é o glioma intrínseco difuso, diagnosticável por ressonância magnética ou biópsia estereotáxica, que responde por $80 \%$ dos casos e resulta em sobrevida curta e má evolução. Como o tronco cerebral é essencial para a vida e não pode ser removido, a cirurgia nesses casos seria mais prejudicial do que benéfica e geralmente não é tentada, o que justifica a reflexão ética sobre o tema ${ }^{6}$.

A influência dos parâmetros éticos na prática da enfermagem também foi abordada, tendo em vista que a autonomia no cuidado do ser humano na área da saúde é o direito que garante a tomada de decisões a partir da informação. Essa é a base do conceito de consentimento livre e esclarecido para escolher racionalmente e aceitar ou não determinado tratamento ou procedimento, conhecendo seus riscos e benefícios.

É importante conhecer as limitações do trabalho e a importância da ação do enfermeiro, que participa da equipe de saúde no processo de cura do paciente, reconhecendo que a autonomia do profissional jamais se sobrepõe à do paciente com lesão crônica ${ }^{7}$. O reconhecimento desses princípios éticos na prática da enfermagem tem sido, ao longo das décadas, um importante fator não apenas de reconhecimento da profissão, mas também de criação de uma identidade própria sempre em defesa dos direitos dos pacientes.

Num país multicultural como o Brasil, é fundamental abordar o tema da bioética e a interculturalidade na atenção à saúde indígena ${ }^{8}$. O princípio da autonomia tem impactos positivos na relação médico-paciente e o equilíbrio entre o tradicional paternalismo médico e a cultura do paciente indígena é fundamental para a simetria. Segundo Bauman ${ }^{9}$, comunidades humanas têm culturas particulares, mas isso não conduz à negação da existência de uma cultura da humanidade.

Cada vez mais, a globalização evidencia que, apesar de importantes diferenças culturais, existe tendencialmente apenas uma civilização, mas o respeito pela autodeterminação dos povos e a afirmação da sua identidade cultural são fatores que emergem de uma nova vaga da globalização com vista a um futuro mais promissor para a humanidade. De acordo com Brighenti ${ }^{10}$, ainda que se considere o "epistemicídio" de práticas e saberes indígenas ocorrido no Brasil, inclusive em relação à territorialidade, uma bioética intercultural na atenção à saúde dos indígenas é possível. Tais conhecimentos podem ser aplicados em outros cenários, onde convivem povos de diferentes culturas.

Por fim, analisa-se a atividade de fiscalização realizada pelos conselhos de classe, cuja função é zelar pela ética e boas práticas profissionais para a proteção da sociedade. Essas entidades são autarquias ${ }^{11}$ criadas em decorrência da descentralização 
das atividades do Estado e surgiram da necessidade da União de criar pessoas jurídicas para atuarem em determinados ramos, como a fiscalização das profissões regulamentadas ${ }^{12}$. Assim, a chamada polícia das profissões, que caberia ao Estado, é delegada às ordens profissionais, que, nessa matéria, exercem atribuições típicas do poder público ${ }^{13}$.

Sendo os sistemas públicos fortemente regulados, as ordens e outras entidades profissionais têm importantes funções de autorregulação profissional. Dessa forma, devem equilibrar os poderes regulatórios de que estão investidas, de modo a defender os interesses dos usuários e promover a integridade profissional.

Estes e outros interessantes temas de pesquisa estão à disposição dos leitores para reflexões.

Boa leitura!

\section{Referências}

1. Catão MO. A covid-19 no brasil e os grupos socialmente vulneráveis: do reconhecimento de necessidades à institucionalização de direitos. SciELO Preptints [Internet]. 2020 [acesso 20 ago 2021]. DOI: 10.1590/SciELOPreprints.508

2. Sen A. Desigualdade reexaminada. $2^{a}$ ed. Rio de Janeiro: Record; 2008.

3. Burlá C, Rego G, Nunes R. Alzheimer, dementia and the living will: a proposal. Med Health Care Philos [Internet]. 2014 [acesso 20 ago 2021];17(3):389-95. DOI: 10.1007/s11019-014-9559-8

4. World Health Organization. Dementia: a public health priority. WHO [Internet]. 2012 [acesso 20 ago 2021]. Disponível: https://bit.ly/3gwelm2

5. Alzheimer's Disease International, McGill University. World Alzheimer Report 2021. Alzheimer's Diseases International [Internet]. 2021 [acesso 20 ago 2021]. Disponível: https://bit.ly/3sKQune

6. Reynolds R, Grant GA. General approaches and considerations for pediatric brain tumors. In: Winn HR, editor. Youmans neurological surgery. $6^{\text {a }}$ ed. Philadelphia: Elsevier; 2011. p. 2040-6.

7. Santiago IS, Carvalho KK. Princípios da bioética e o cuidado na enfermagem [Internet]. In: Anais do $1^{\circ}$ Congresso Internacional de Filosofia Moral e Política; 9-12 nov 2009; Pelotas. Pelotas: Universidade Federal de Pelotas; 2009 [acesso 20 ago 2021]. Disponível: https://bit.ly/38eLbD6

8. Santos ACG, lamarino APM, Silva JB, Zollner ACR, Constantino CF. Considerações bioéticas sobre a relação médico-paciente indígena. Rev. bioét. (Impr.) [Internet]. 2017 [acesso 20 ago 2021];25(3):603-10. DOI: 10.1590/1983-80422017253217

9. Bauman Z. Ensaios sobre o conceito de cultura. Rio de Janeiro: Zahar; 2012.

10. Brighenti CA. Colonialidade do poder e a violência contra os povos indígenas. PerCursos [Internet]. 2016 [acesso 21 ago 2021];16(32):103-20. DOI: 10.5965/1984724616322015103

11. Medauar O. Direito administrativo moderno. $5^{a}$ ed. São Paulo: Revista dos Tribunais; 2001. p. 108.

12. Santos AL, Jacobs E. Os conselhos de fiscalização de profissões regulamentadas. Jacobs [Internet]. 2020 [acesso 21 ago 2021]. Disponível: https://bit.ly/3gtZyYQ

13. Magami RT Jr. O poder de polícia (ou limitação administrativa à liberdade e à propriedade) como instrumento de desenvolvimento econômico e social. Jus.com.br [Internet]. 2016 [acesso 21 ago 2021]. Disponível: https://bit.ly/3ze59Kj 
Tatiana Bragança de Azevedo Della Giustina - Doutora - tatiana.giustina@ portalmedico.org.br (D) 0000-0001-5905-4722

José Hiran da Silva Gallo - Doutor - gallo@portalmedico.org.br (D) 0000-0002-1848-7270

Rui Nunes - Doutor - ruinunes@med.up.pt

(D) 0000-0002-1377-9899 